\title{
Analysis on Several Heat Pump Applications in Large Public Buildings
}

\author{
Shengchun Liu1 ${ }^{*}$, Wenkai Zhang1, Ziteng Dong1, Gang Sun² \\ ${ }^{1}$ Tianjin Key Laboratory of Refrigeration Technology, Tianjin University of Commerce, Tianjin, China \\ ${ }^{2}$ China Aviation Planning and Construction Development Co., Ltd., Beijing, China \\ Email:
}

Received 28 July 2015; accepted 19 September 2015; published 22 September 2015

Copyright (C) 2015 by authors and Scientific Research Publishing Inc.

This work is licensed under the Creative Commons Attribution International License (CC BY).

http://creativecommons.org/licenses/by/4.0/

(c) () D Den Access

\begin{abstract}
The consumption of cooling and heating energy and the methods of heating and cooling used in large public buildings are analyzed in this paper. A comparison between initial investment and operation costs of heat pump and traditional heating modes used in large public buildings is also introduced. A life cycle cost (LCC) mathematical model is established to analyze the main factors that affect the LCC including the advantages and disadvantages of heat pumps currently in use. Some suggestions about heating and cooling modes applied in large buildings in different geographical areas are given in this paper.
\end{abstract}

\section{Keywords}

Large Public Buildings, Heat Pump Heating and Cooling, LCC, Economic Analysis

\section{Introduction}

With the increasing urban environmental requirements, energy supply structures are gradually changing. To improve building energy efficiency, the options used for heating and cooling have increased in diversity. Existing methods have geographically specific rationalities during selection of heating and cooling systems. Local climatic conditions, environmental requirements, fuel availability, energy efficiency, affordability and other factors should be considered. The way with how to properly evaluate the energy consumption of a heating and cooling system is the most important, for comparison decisions. Energy consumption of various types of buildings contrasts significantly. Public building energy consumption reached $19.4 \%$, compared to urban residential which reached $17.7 \%$ of total energy consumption in China's built environment. Public buildings consume more energy than the residential housing, but the total number of public buildings is fewer than residential. Air condition-

\footnotetext{
${ }^{*}$ Corresponding author.
}

How to cite this paper: Liu, S.C., Zhang, W.K., Dong, Z.T. and Sun, G. (2015) Analysis on Several Heat Pump Applications in Large Public Buildings. Journal of Building Construction and Planning Research, 3, 136-148. 
ing accounts for $37 \%$ to $50 \%$ [1] of energy used. Many studies [2]-[5] on specific regions and modes about heating and cooling have been done in previous research, however, taking the origin, transport requirements and price of energy into consideration, little economic research comparing different regions and climate conditions about different heating and cooling modes has been done. Many programs can be used in district heating and cooling systems which only consider economic aspects in a simple source evaluation and ignore functional differences that may problematic in actual operation and management, causing poor performance, low energy savings, poor environmental benefits, etc.

For the problems listed, to make cooling and heating technology and economic indicators which optimized for large public buildings life cycle cost (LCC) and value engineering principles are discussed in this article. Taking the origin, transport aspects and price of energy into consideration in different regions and climate conditions, an analysis of life cycle costs of several modes of heating and cooling, heat pump heating and cooling, coal-fired boiler + water chilling unit, gas fired boiler + water chilling unit, oil fired boiler + water chilling unit, currently used in large public buildings is considered. To determine the best large-scale public buildings cooling and heating options, the best technical and economic indicators, life cycle costs and value engineering ideas are applied. Several heating and cooling modes heat pump heating and cooling, coal-fired boiler + water chilling unit, gas fired boiler + water chilling unit, oil fired boiler + water chilling unit in large domestic public buildings are conducted by considering the energy price differences of climatic regions, location of production and transportation costs. The initial investment for large public buildings and a visual representation of the running cost models and diagrams are given.

Establishing the LCC model depends on the climatic conditions in different regions in China, different heat sources, investment in different devices, and the same amount of heating and cooling constraints and objective functions. The main factors in different areas to achieve the goal of minimizing LCC costs, combined with constraints were used to compute optimized scenarios. Feasible recommendations for large public buildings in a wide range of cooling and heating scenarios are proposed through analysis of survey data and theoretical calculations. Suggested engineering practice guidance to further promote the development of district heating and cooling is provided.

\section{Analysis of Various Heating and Cooling Modes}

\subsection{Comparison of the Initial Investment}

The comparison between a ground source heat pump air conditioner and traditional air conditioner of the initial investment is provided in Table 1. Figure 1 shows the initial investment of different heating modes. While calculating the initial investment has including all items from cool and heat source, pipe network and interior terminal. The heating investment of the heat pump is higher than the boiler, because the ground source heat pump can heat and refrigerate, so the initial investment of ground heat pump should be less than the gross investment of two systems includes boiler and cooling air conditioner [6].

The formula of the initial investment for heating and cooling in large public buildings is:

$$
F=A+B+C+D+E
$$

$A$-Part and parcel of the boiler [Ten thousand Yuan];

$B$ - Auxiliary machinery equipment [Ten thousand Yuan];

$C$-Installation charge of boiler, $(A+B) \times 30 \%$ is generally fetch on the engineering [Ten thousand Yuan];

$D$-Installation charge of boiler room [Ten thousand Yuan];

E-Cooling air conditioner cost [Ten thousand Yuan].

In Table 1, the relevant economic parameters of initial investment projects can be calculated from the initial investment of several heating and cooling mode by means of cash flow method. Compared with other traditional modes, ground-source heat pump needs the cost of drilling and underground pipe, while several other models need to be invested in the cooling tower. With the increasing of the heating area, the initial investment has obvious advantages compared with other ground source heat pump model [7]. Among several traditional model under the same conditions, the oil-fired boiler and chiller are the highest initial investment, then followed by gas boiler and Water chilling unit, the lowest is coal-fired boiler Water chilling unit Mainly because gas-fired boiler and oil-fired boilers can recycle the waste heat from the exhaust of gas or diesel engines and cooling water, which can reduce the heat pump heating design capacity and the initial investment. At the same time the fuel 
Table 1. The initial investment of soil heat pump and traditional air conditioner.

\begin{tabular}{|c|c|c|c|c|}
\hline \multirow{2}{*}{$\begin{array}{l}\text { Cold and heat source type and } \\
\text { serial number }\end{array}$} & 1 & 2 & 3 & 4 \\
\hline & $\begin{array}{l}\text { Ground source } \\
\text { heat pump }\end{array}$ & $\begin{array}{l}\text { coal-fired boiler }+ \\
\text { Water chilling unit }\end{array}$ & $\begin{array}{c}\text { Gas boiler }+ \\
\text { Water chilling unit }\end{array}$ & $\begin{array}{c}\text { oil boiler }+ \\
\text { Water chilling unit }\end{array}$ \\
\hline Cold and hot water unit (yuan/kW cooling) & $680-1000$ & $560-800$ & $560-800$ & $560-800$ \\
\hline Boiler (yuan/kW heating) & No & $400-520$ & $400-620$ & $560-650$ \\
\hline Cooling tower (yuan/kW cooling) & \multicolumn{4}{|c|}{$40-60$} \\
\hline Drill hole and bury pipe (yuan/kW) & $1200-2000$ & \multicolumn{3}{|c|}{ No } \\
\hline $\begin{array}{l}\text { Water pump, pipeline, controlling, } \\
\text { etc. of engine room }\end{array}$ & \multicolumn{4}{|c|}{ Basically the same (20 - 40 yuan $/ \mathrm{m}^{2}$ ) } \\
\hline Air conditioner terminal of the building & \multicolumn{4}{|c|}{ Basically the same (100 - 180 yuan $\left./ \mathrm{m}^{2}\right)$} \\
\hline The initia & omparison of bu & tary estimate (Heatin & index $75 \mathrm{~W} / \mathrm{m}^{2}$ ) & \\
\hline
\end{tabular}

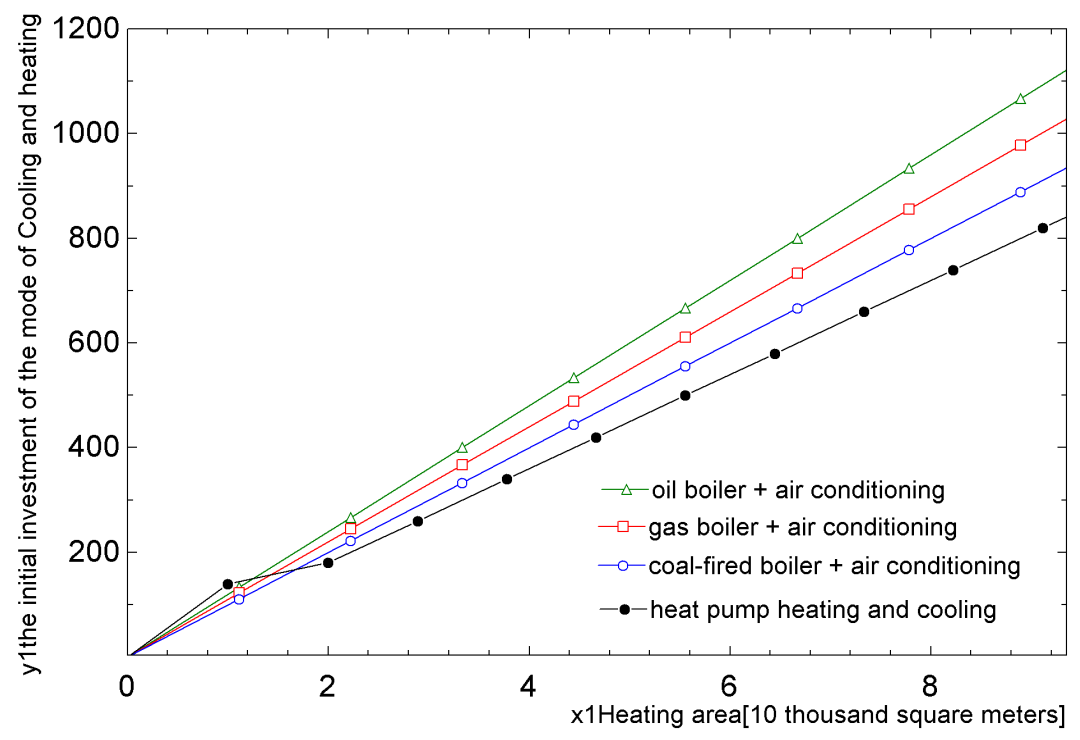

Figure 1. The initial investment of several heating and cooling modes.

pump and gas heat pump need additional electrical capacity expansion fees and gas installation fees respectively. When other conditions are same, the system initial investment using oil-fired boiler as early maximum auxiliary boilers is the highest, followed by gas-fired boiler, and the initial investment using coal-fired boiler is the lowest. When the capacity of auxiliary boilers is same, with the increase of the capacity of the auxiliary heat source the system initial investment reduces.

The different heating area and initial investment curve in Figure 1 calculate through the investment of different equipment and heating (cooling) resource. While the comparison of heating cost that use different heating modes can obtain by considering the time factor of fund and resource price through thermo-economic analysis (Figure 2).

\subsection{The Comparison of Heat Pump and Energy Price}

The mathematical model of cost first to use the whole life cycle cost method to analyze the heat pump system is set up. Calculating its life cycle cost mainly consider the construction and operation cost of the system, According the initial investment, operation cost, management cost, scrap value and amendment of economic factors, the mathematical model of $L C C$ is [8]:

$$
L C C=I C+\sum_{K=1}^{n} O C(1+i)^{-k}+D C(1+i)^{-n}
$$




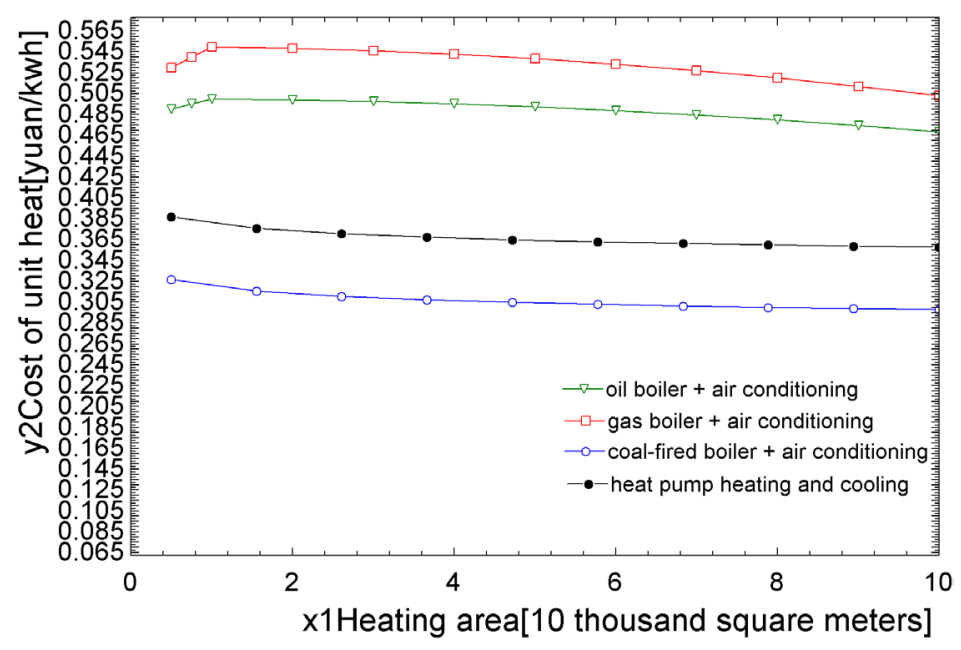

Figure 2. Cost comparison of several heating modes.

LCC—Whole life cycle cost;

IC-The initial investment value;

OC-Operation cost;

$D C$ - Scrap value;

$k$-Time of the equipment has been used;

$n$-Economic life.

Ignore the factors of the energy price fluctuation, it can simplify to:

$$
L C C=I C+O C \frac{(1+i)^{n-1}}{i(1+i)^{n}}+D C(1+i)^{-n}
$$

Heat pump is advanced compared with coal-fired, gas, and oil boiler. Compared comprehensively, take the cost that produces $50 \mathrm{MJ}$ heat needs in Beijing area as an example:

1) Heat pump: Suppose the COP (ratio of heat produce to electric energy consumed, i.e. the coefficient of performance of the unit) value of the heat pump as 4 , then the power consumption is $2.50 \mathrm{KW}$, If the average price of the electricity is $1 \mathrm{yuan} / \mathrm{kWh}$ (Beijing area), then the cost of electricity, set as $Z_{1}$, is: $2.50 \times 1=2.50 \mathrm{yu}$ an;

2) Coal-fired boiler: About $70 \%$ of the coal can produce heat, then the necessary fuel is $2.13 \mathrm{~kg}$. If the coal price is $0.75 \mathrm{Yuan} / \mathrm{kg}$, the cost is, set as $Z_{2}: 2.13 \times 0.75$ Yuan $=1.60$ yuan;

3) Gas fired boiler: About $75 \%$ of the gas can produce heat, then the necessary fuel is $3.81 \mathrm{~m}^{3}$. If the gas price is 3.50 Yuan $/ \mathrm{m}^{3}$, the cost is, set as $Z_{3}: 3.81 \times 3.50$ Yuan = 13.34 Yuan;

4) Oil fired boiler: About $80 \%$ of the oil can produce heat, and then the necessary fuel is $1.16 \mathrm{~L}$. If the oil price is 5 Yuan/L the cost is, set as $Z_{4}: 1.16 \times 5.0$ Yuan $=5.80$ Yuan.

In this paper, the heat index is $100 \mathrm{kcal} / \mathrm{m}^{2}$, the economic life $\mathrm{n}$ is $50,10,000 \mathrm{~m}^{2}$ heat consumption of buildings in North China is:

$$
Q=75 \mathrm{~W} \times 24(\mathrm{~h}) \times 3600 \times 10000\left(\mathrm{~m}^{2}\right) \times 150(\mathrm{~d})=9.723 \times 10^{12} \mathrm{~J}
$$

Figure 3 shows the comparison that cost of producing 42,000,000 J heat by several heating modes in Beijing.

The cooling mode of large public building in summer is powered by electricity, its COP mainly arranges from 3.2 to 4.5 [9], so the operate expense disparity is small.

The scrape value and the cooling cost in summer is ignored, to analyze the initial investment and operate cost, $L C C$ is used, the formula mentioned above can simplify to [10]:

$$
L C C=Y_{1}+Z \times Q \times X_{1}
$$

Figure 4 is the $L C C$ clear display. 


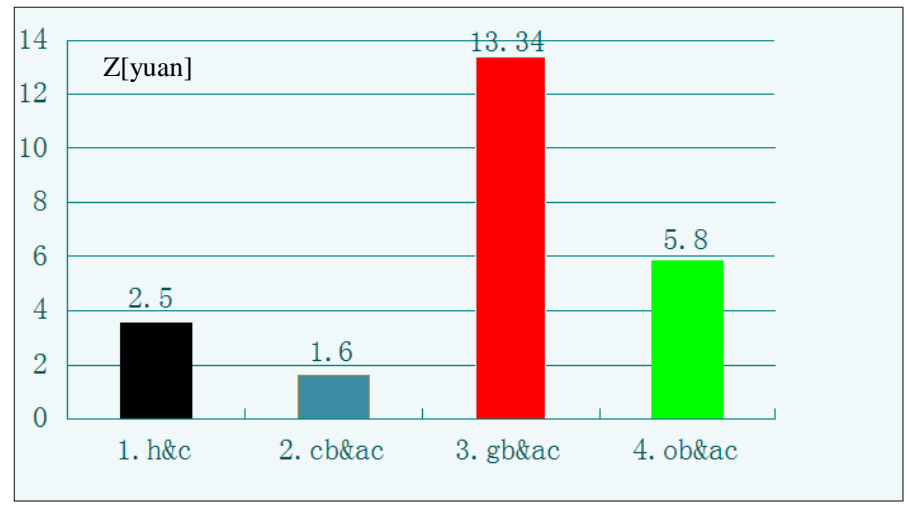

Figure 3. The cost that produces $50 \mathrm{MJ}$ heat needs in Beijing.

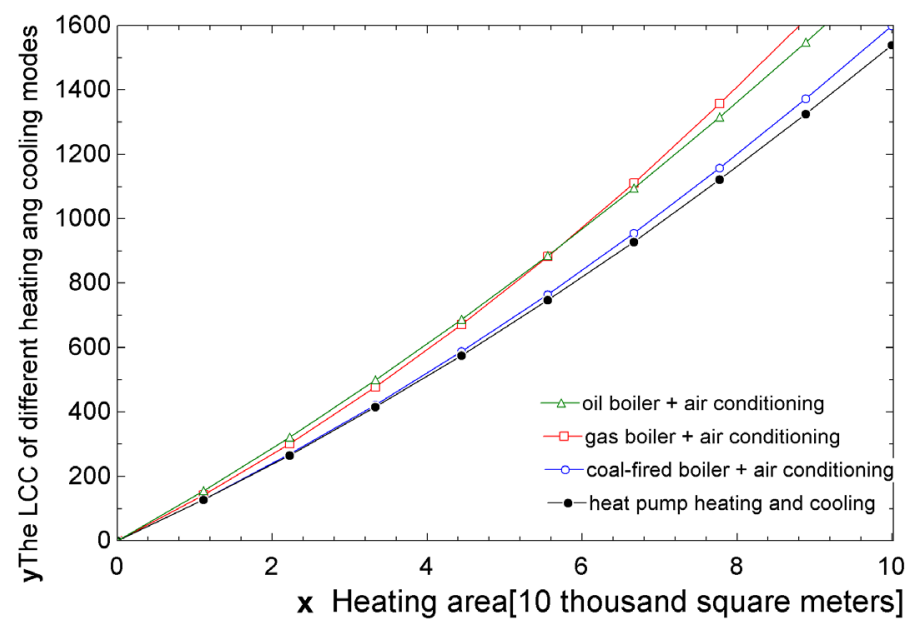

Figure 4. LCC comparison of heating and cooling.

The comparison of LCC in Figure 4 at different heating area and the same heat load is calculate through the initial investment in Figure 1 and the operation cost in Figure 2 under the consideration of the time factor of fund by the formula of $L C C$.

Therefore, among other heating and cooling modes in large public buildings, the heat pump is more superior at the energy consumption, and the heat pump applications will be at the high-speed ascending development stage and have a bright future as a energy save technology. Many enterprises realize the energy-conservation and environmental protection benefit that the heat pump can bring .The market data indicate a good development trend in the future, so in general, the heat pump has advantages taking initial investment, operate cost and environmental protection into consideration [11].

\section{Advantages and Disadvantages of Several Heat Pump}

Heat pump is an energy-conservation technology, which has a sustainable development trend. Several kinds of cooling and heating modes described above are analyzed from efficiency of the heat pump system. Through the comparative analysis of the heat pump system and regular system, the obvious advantage of the heat pump in energy-conservation and economic benefits are obtained [12]. Nagano, et al. [13] have designed the passive low energy consumption building integrating the ground source heat pump, which changes the ground source heat pump system operation way by measuring its energy consumption of the whole year, temperature and humidity of the automatically controlled ventilating system. Finally, the high-efficient control methods that to guarantee the comfortableness and low energy consumption are made by developing the applicable simulation. Itoh, et al. [14] realize the low carbon architectural design by adopting the heat pump and heat storage technology and combining the ground source heat pump with air source heat pump, and he reduces the energy consumption of 
buildings effectively by adopting the latent heat stored system combining the energy administrative system. The actual operation efficiency, energy-conserving potentiality, etc. of heat pump system have relationship with systematic design and operation conditions, but no comprehensive discussions of energy-conserving benefit, economic benefits, and environmental benefit of the heat pump was made. Some advantages and disadvantages of heat pump and some kinds of heating and cooling modes that used in large public buildings are present in this article. Characteristics of heating modes that mainly used in China are given in Table 2 [15].

\subsection{Air Source Heat Pump}

The air source heat pump mainly utilizes heat that stored in the air. The air source heat pump is without apparatus such as the cooling tower, cooling water pump, cooling water treatment. It reduces the managerial work load, operation maintenance, and improves the operate dependability. No cooling tower means nonexistence of mists and impact on surrounding environment of the noise [16]. These two characteristics makes air source heat pump operate during northern transition season. This is a benefit that any other cold water chiller cannot compete.

1) The wide applicable temperature range, the high utilization ratio of energy, it is environmental protection, and convenient to install;

2) Air source heat pump is energy-conserving product, its power consumption is just $1 / 4$ of that of the electric boiler for the whole year. Compared with coal, oil and gas fired boiler, it can save more than $40 \%$ energy, and can regain investment shortly [17];

3) The occupation of land space is very small, can reduce by $95 \%$ of the floor space compared with apparatus of solar energy, can reduce the area of the water tank, and make the initial investment reduce effectively;

4) It can operate automatically and steadily, safely. And its maintain cost is low. Compared with the traditional cold water chiller, it has no cooling tower and the cooling water pipe, sparing the operation cost effectively.

The air source heat pump also has limitation in application, such as, the external condition have great impact on air source heat pump use. Outdoor low air temperature will reduce the heating capacity and COP. In addition, the ordinary air source heat pump will frost easily when environmental temperature below zero. By calculating, in the general heat pump device, only $30.18 \%$ of the compressor work is utilized, the compressor and condenser loss among them and can account for $50 \%$ to compress work. The evaporator efficiency will drop greatly when the outdoor air temperature is low. To keep higher working efficiency, the evaporator needs frequent defrosting, which will raise the expenses of operating [18].

\subsection{Water Source Heat Pump}

The water source heat pump uses solar energy that the water stores as the cold and heat source, and the heat pump

Table 2. Character of heating mode of China at present.

\begin{tabular}{|c|c|c|}
\hline Concrete way & Advantage & Disadvantage \\
\hline Heating by coal-fired boiler & $\begin{array}{l}\text { Energy-conservation, economy, higher environmental } \\
\text { protection benefit }\end{array}$ & $\begin{array}{l}\text { Big investment, long construction period, } \\
\text { accident happen easily and high management } \\
\text { cost }\end{array}$ \\
\hline $\begin{array}{l}\text { Heating by coal-fired boiler } \\
\text { (central Heating by boiler) }\end{array}$ & $\begin{array}{l}\text { Energy-conservation, good environmental protection } \\
\text { and operational efficiency, small investment, short } \\
\text { construction period. }\end{array}$ & $\begin{array}{l}\text { Disperse and small-scale coal-burning boiler } \\
\text { thermal efficiency low, dispel smoke and dust } \\
\text { to be result bad }\end{array}$ \\
\hline $\begin{array}{l}\text { Heating by oil (gas) boiler } \\
\text { (Heating water system) }\end{array}$ & $\begin{array}{l}\text { Clean, environmental protection, regulate flexibly, } \\
\text { energy-conservation, install simply, easy to operate }\end{array}$ & High operation cost than coal-fired boiler \\
\hline Wind system of gas heating & $\begin{array}{l}\text { Clean, environmental protection, regulate flexibly, } \\
\text { energy-conservation, install simply, easy to operate }\end{array}$ & High operation cost than coal-fired boiler \\
\hline Air source heat pump & It is high in efficiency to make heat & $\begin{array}{l}\text { Heat efficiency drop with decline of outdoor } \\
\text { temperature, or apt district to marry frost } \\
\text { unsuitable to use in severe cold }\end{array}$ \\
\hline Water source heat pump & $\begin{array}{l}\text { Water hot capacity is large Refrigeration efficiency } \\
\text { (COP) of the general water source heat pump Higher } \\
\text { than the air source heat pump }\end{array}$ & Restricted by source of water \\
\hline Ground source heat pump & $\begin{array}{l}\text { Economy, effective, energy-conservation, } \\
\text { environmental protection }\end{array}$ & $\begin{array}{l}\text { The investment higher for the first time, May } \\
\text { influence the environment }\end{array}$ \\
\hline
\end{tabular}


system make energy transfer. There are many factors that influence the water source heat pump system, for example climatic conditions, characteristic of the building, system form, run and control etc., and these factors can mutual coupling influence the whole system.

1) Water source heat pump draws the low-grade heat energy from the water and its own water temperature change little, the unit operates steadier, and its COP can be up to 3.5 - 4.4;

2) As to air source heat pump, the water source heat pump have no the defrost device, making the operation cost of the apparatus reduce greatly;

3) The water source heat pump generally uses electric as energy, as to coastal cities, a well design water source heat pump can save $30 \%$ of the electric energy;

4) Water source heat pump applied widely, it can offer hot water at the same time while heating or cooling. It has obvious advantages than others [19].

Facing the better operation result, the water source heat pump faces some problems. The usable water resource is limited, the systematic investment of closing type is relatively high, and low heat transfer efficiency, but the source of water limits the development of open type system, though the usable water areas are numerous, in reality, the water resources utilization cost in different areas is widely different, water temperature meets the demand of heat pump design and local legal requirement. The biggest problem lies in high initial investment and it also increase the later operation and maintain cost. It is high of systematic global design requirement, including the choice of the water pump, the resistance equilibrium question in the waterway, and the repeated use problem of pumping and recharge well.

\subsection{Ground Source Heat Pump}

Ground source heat pump utilize the characteristic that underground soil temperature relatively stable, a apparatus that exchange heat with buildings around through pipeline system bury deeply. It collects heat from the soil in winter and heating the building; Discharge heat to soil and cooling the building in summer. It uses soil as the heat and cold source, heating and cooling the buildings through the high-efficient heat pump.

1) The energy efficiency ratio of high-efficient heat pump can reach more than $4.0 \mathrm{~kW} / \mathrm{kW}$, energy consumption can save about $40 \%$ in the whole year, the area of computer lab is relatively small, save the regular systematic considerable amount of water consumed of cooling tower, and the operation cost is low;

2) Does not produce any harmful substance, pollution-free to the environment; realize the efficiency of environmental protection;

3) There is little external disturbance to bury pipe, stability, dependability. Will not cause waste and will not destroy the water resource, applicable in extensive range, maintenance and operating cost is low and it is long-lived;

4) As to ground source heat pump, there is no region limited basically [20].

At present, some limits exist yet as to the soil source heat pump. For example the soil temperature will influence it greatly, and it needs electricity putting into the system when soil temperature is low in winter, and this will increase the operation cost. It will cause influence on soil temperature when operate continuously for a long time, cause the operation dependability decline of the unit, cause destroying to the ecology at the same time, and heat conduction coefficient is little, need greater heat exchange area, need larger place to construct, make the initial investment increase [21].

\section{Results and Discussion}

The LCC mathematical model is a mixed planning problem by 0 - 1 [22], it sums up the cooling and heating system optimization question as different areas, different cold and heat source, different energy price, different equipment investment, and the same cooling or heating amount, as the constraint condition of optimal allocation question. the dynamic technological methodology of economic evaluation, time and value factors of fund are considered, aimed at the minimum LCC discount, calculate combine the constraint condition. The model is summed up as follows:

Objective function:

$$
Z=\sum_{i=1}^{m} F_{i} Z_{i}+\sum_{i=1}^{m} \sum_{k=1}^{k_{i}} F_{i k} Y_{i k}+\sum_{i=1}^{m} \sum_{k=1}^{k_{i}} \sum_{j=1}^{n} C_{i k j}
$$


Constraint condition:

$$
\begin{aligned}
& \sum_{k=1}^{k_{i}} S_{i k} Y_{i k} \leq Q_{i}^{\max }, \quad i=1,2, \cdots, m \\
& \sum_{k=1}^{k_{i}} Y_{i k} \leq P_{i} Z_{i}, \quad i=1,2, \cdots, m \\
& Z_{i}, Y_{i k}=0 \text { or } 1, \quad X_{i k j} \geq 0
\end{aligned}
$$

Among them, $\mathrm{m}$ is the amount of the cold and heat source that waiting to select; $k_{i}=\left\{1,2, \cdots, P_{i}\right\}$ is the amount of possible installation heat apparatus in heat and cold source that waiting to select; $n$ is equal to the whole area of large public buildings $/ 100 \mathrm{~m}^{2}$. Set $F_{i}$ as the fixed expenses (annual fixed expenses sum that discount) of life cycle of unit user for $i$ cold and heat source. $F_{i k}$ is the fixed expenses (annual fixed expenses sum that discount) of install $k$ heat apparatus in the life cycle in $i$ heat and cold source. $C_{i k j}$ is the transport expense of the $k$ apparatus in $i$ heat and cold source that produced by bearing the variable produce of user $j . C_{i k j}=P_{i k j}+T_{i k j}$, among them $P_{i k j}$ is the variable producing cost in life cycle of the unit heat load; $T_{i k j}$ is the transport expenses in life cycle of the unit heat load; $S_{i k}$ is the max heating and cooling ability of k apparatus in i heat and cold source; $Q_{\max i}$ is the max heating and cooling ability in $i$ heat and cold source; $Y_{i k}$ is $0-1$ variables, $Y_{i k}=1$ means this equipment is installed or set up, otherwise is not installed or set up; $Z_{i}$ is $0-1$ variables, $Z_{i}=1$ means to install or set up $i$ heat and cold source, otherwise means there is no this heating and cooling mode or not set up.

Among them, $F_{i}$ can be interpreted as the initial investment of cooling and heating, $C_{i j k}$ of a kind of apparatus can be interpreted as the operating cost of the whole system, two kinds of main factors that influence $C_{i j k}$ are $P_{i k j}$ and $T_{i k j}$, to the several kinds of heating and cooling modes analyzed in this text, $P_{i k j}$ is the variable producing cost in life cycle of the unit heat load, mainly influenced by the energy prices of different areas, and $T_{i k j}$ is the transport expenses in life cycle of the unit heat load, mainly influenced by the cop of the whole heating and cooling system. For example, the area not close to the source of water, and the coal resource is relatively deficient like Beijing, the influence of $P_{i k j}$ and $T_{i k j}$ is not big in disparity in Figure 3, while the influence of $T_{i k j}$ is greater than that of $P_{i k j}$, so the soil source heat pump have advantages by other modes on total cost, so the author proposes using the air source or soil source heat pump for cooling and heating.

From the comparison analysis above, there are pluses and minuses in various heat pump air conditioner and other heating and cooling modes, but some factors such as local climate, hydrology geological condition, geographical condition and building load, etc should be considered. Among them, the environment influence of air source heat pump is obviously greater than the sources of water and soil heat pumps, but it is convenient to fix up and install. The water source heat pump operates stability and is the most effective but restricted by environment and resources obviously. There is no limitation in application of soil source heat pump while heat exchange coefficient is small and efficiency is low. So some suggestions following are provided of the cooling and heating for large public buildings in China:

1) The climate distribution of China is provided in Figure 5. $T_{i k j}$ is the transport expenses in life cycle of the unit heat load, mainly influenced by cop of the whole cooling and heating system in severe cold and extremely cold area. Extremely cold area dissipates more heat when heating in winter. And there is little influence on heating and cooling modes [23], so propose adopting the coal-fired boiler central heating in winter, adopting the air source or water source heat pump cooling in summer. Such as in Harbin, Hailaer area, can join the heating pipe network of urban for heating, install the air source heat pump indoors for cooling;

2) The influence of $P_{i k j}$ and $T_{i k j}$ has little disparity in eastern coastal area, the area along the lake or river as it shown in Figure 6, while the influence of $F_{i}$ is greater than that of $C_{i j k}$, if the law is allowed, can adopt water source heat pump to heating and cooling, the water source heat pump type should analyze case by case. It can adopt the water source heat pump such as Shanghai, areas such as Qingdao, etc.;

3) Figure 7 provides the distribution of different areas of China. $P_{i k j}$ is the variable producing cost of life cycle of unit heat load, the solar energy will affect the other energy price in plenty sunshine area. It can use the solar energy assist heat pump in the area that sunshine duration is greater than 700 in a year;

4) Such as Figure 8, in the areas that the south of the Yangtze River, if the water source heat pump condition is not allowed, it can adopt the ground source heat pump + air source heat pump. In Chongqing and Kunming area, the outdoor air and soil temperature is high, while the influence of $P_{i k j}$ and $T_{i k j}$ is small, the influence of $F_{i}$ 
becomes the leading factor, it can adopt the air source or ground source heat pump;

5) The coal resource distribution of china is provided in Figure 9. The influence of $P_{i k j}$ is far greater than that of $T_{i k j}$ considered the factors that low coal cost and the development of coal heating in the middle areas that not along the river or lake where the coal resource is not plenty. It can adopt the central heating of coal-fired boiler

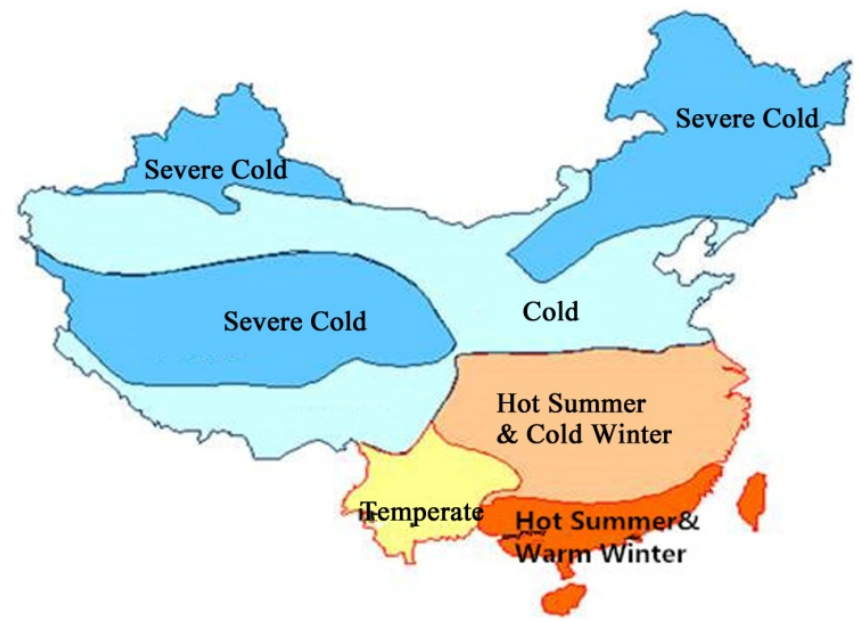

Figure 5. Climate distribution map.

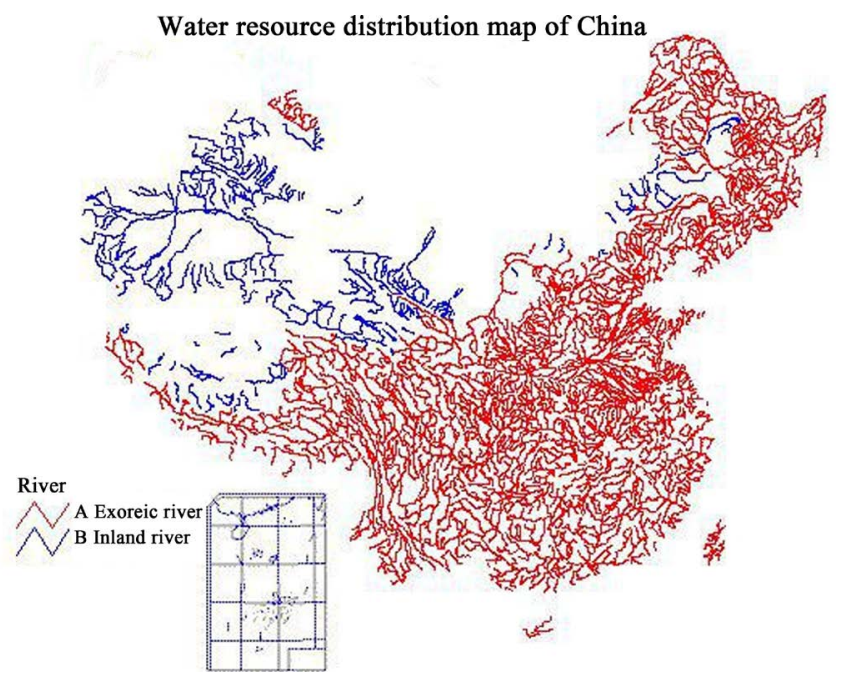

Figure 6. Water resource distribution map of China.

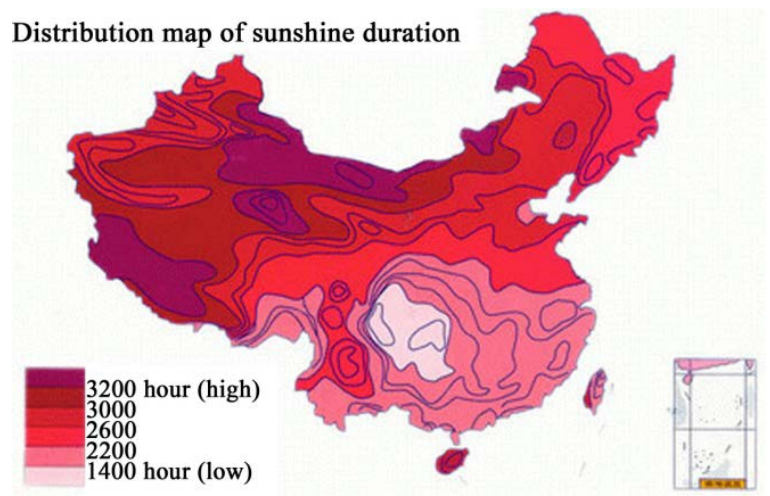

Figure 7. Distribution map of sunshine duration. 


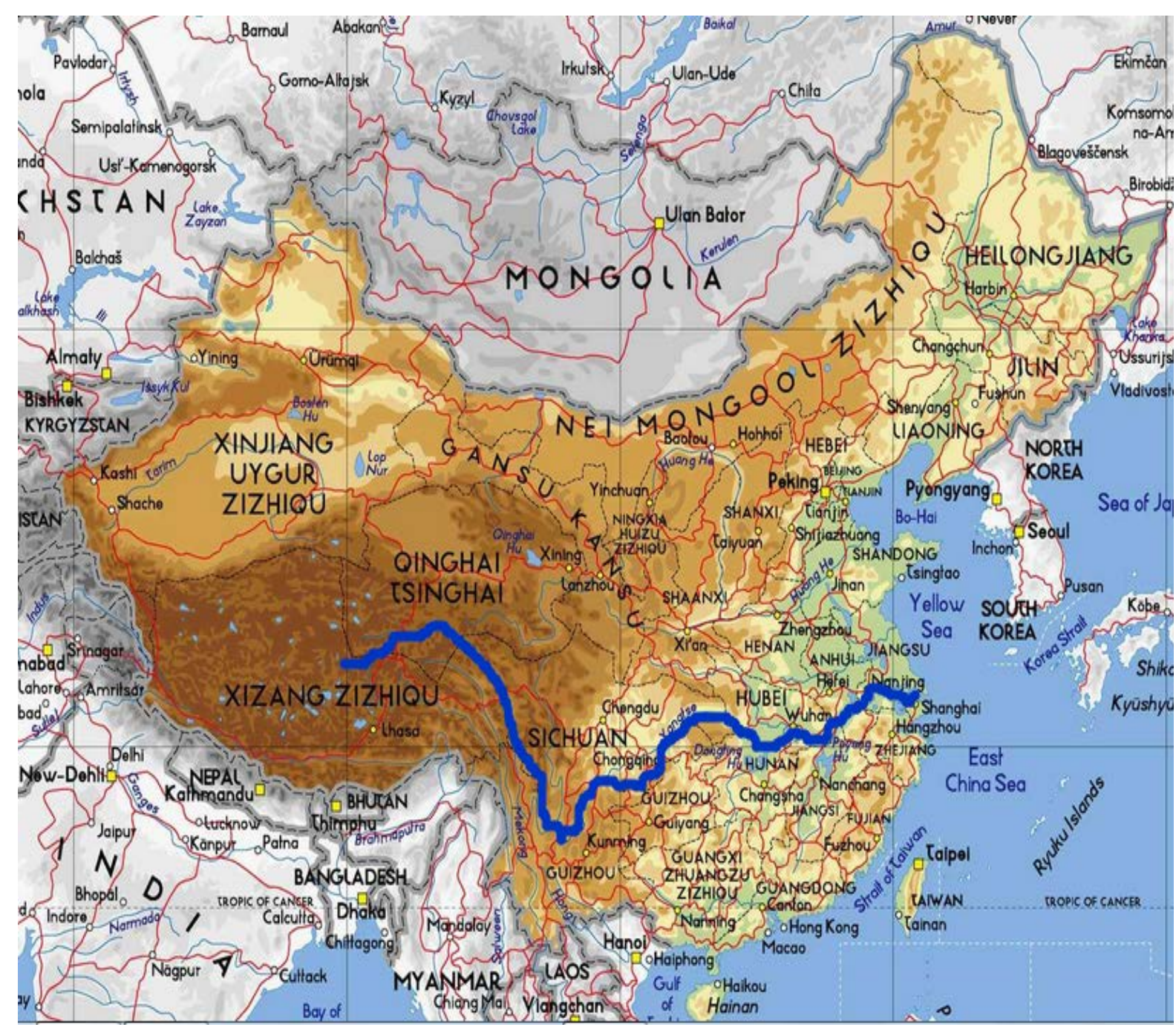

Figure 8. Map of China.

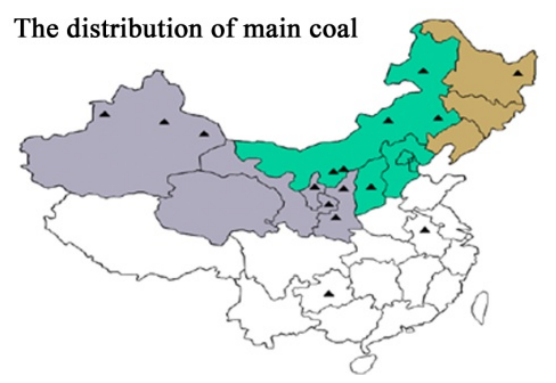

Figure 9. Coal resource distribution map of China.

+ air source heat pump, such as DaTong, Pingdingshan area;

6) The influence of $P_{i k j}$ and $T_{i k j}$ In the areas where is not close to the water and lack of coal is small, the influence of $F_{i}$ becomes the leading factor, the author suggest adopting the air source + ground source heat pump to cooling and heating such as Beijing area;

7) The main oil and gas field distribution of China is provided in Figure 10. The influence of $P_{i k j}$ is far greater than that of $T_{i k j}$ in the western region where the oil and gas resource is plenty and hart to transport can adopt the gas boiler + solar energy assist to cooling and heating. 


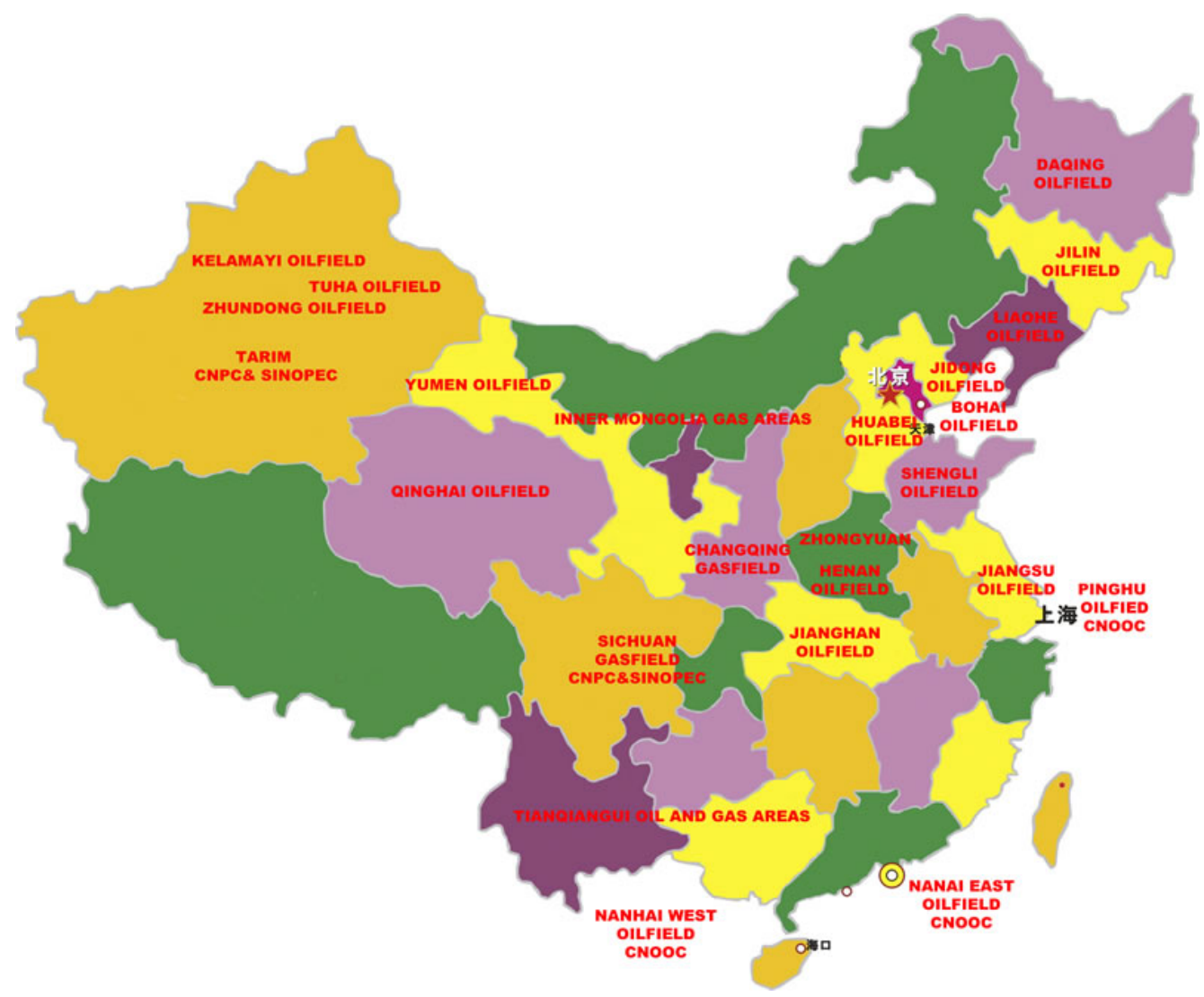

Figure 10. Main distribution map of oil and gas field in China.

\section{Conclusions and Prospect}

\subsection{Conclusions}

The consumption of cooling and heating energy and the methods of heating and cooling used in large public buildings are analyzed in this paper. The principle of life cycle cost method and the value engineering are applied. By considering the different origins and energy price difference caused by the current transport several domestic large public buildings heating cooling (heat pump heating and cooling, coal-fired boiler + water chilling unit, gas boiler + Water chilling unit, oil boiler + Water chilling unit), these conclusion can be arrived:

1) For large public buildings, several heating and cooling ways that applied mainly at present carrying on the analysis of life cycle cost, through different area, different climate and the energy price difference caused by producing area and transportation;

2) It considers the influence of all kinds of energy prices and the difference caused by the production and transport caused by different forms of cooling. So when select the way of heating and cooling, the different prices of energy must be considered;

3) In this paper, the economy of China large public buildings application mainly several heating and cooling modes. Through the analysis, the heat pump is better than the traditional model in economy and technology;

4) The scheme of DHC is set up according to investment, the operating cost, and scrap value of the beginning of LCC pattern analysis. We offer the suggestion to use heating and cooling of large public buildings for different climate and different areas.

\subsection{Prospection}

The advantages and disadvantages of several kinds of heating and cooling modes are analyzed under the effect of different climatic conditions and the law of value in different areas. Some suggestions of large public buildings heating and cooling mode are given. On the basis of the study, aiming at the shortcomings of the existing 
researches, the following aspects can be done deeply.

1) The right heating and cooling mode can be chosen depending on the regional climate conditions and energy characteristics, the different refrigerant effects on the entire system can be explored deeply. And the heat pump form of different regions and times can be optimized based on the law of market value;

2) Based on the established LCC model and the main factors and the secondary factors influencing the system, the appropriate constraints can be selected to linearize some nonlinear factors by selecting the appropriate constraints depend on overall planning and optimization. Then the large public buildings corresponding cooling and heating mode can be optimized;

3) With the continuous development of new energy sources (such as bio-energy, shale gas), different new clean energy must be introduced into LCC model and real problems timely. The optimal cooling and heating of large public buildings mode can be obtained by researching the economy, environmental protection, stability, controllability of new energy.

\section{Acknowledgements}

The work in this paper is supported by the science research innovation team project in Tianjin city, China. "Energy saving of equipment in food cold chain and new technologies in refrigerated transportation" (TD125048).

\section{References}

[1] Wei, Q.P. (2009) The Energy Consumption and Characteristic of Public Buildings in China. Construction Science and Technology, 4, 38-43.

[2] Wu, M.H. (2007) The Research on the Application of Surface Water Heat Pumps in Chongqing. Chongqing University, Chongqing, 1-91.

[3] Yang, W.F. (2010) Study on the Economy of GSHPs' Application in the New Buildings and the Policy Suggestion. Xi'an University of Architecture and Technology, Xi'an, 1-61.

[4] Qian, C. (2008) The Evaluation of Ground-Coupled Heat Pump System in Different Climatic Region. China Academy of Building Research, Beijing, 1-63.

[5] Zhang, C.H. (2007) The Life Cycle Cost Evaluation of Schemes and Analysis of Key Parameters in District Cooling and Heating System. Dalian University of Technology, Dalian, 68-70.

[6] Zhu, C.-X. (2005) Technical and Economic Discussion of Several Common City Heating Methods. Journal of Henan University of Science and Technology, 26, 72-73.

[7] Shi, Y.J. (1999) Application of LCC to Optimization of Heating Systems. Journal of HV\&AC, 29, 65-66.

[8] Unal, C. (2015) Numerical Modeling of a Ground Source Heat Pump: The Bolu Case. Renewable Energy, 45, $352-361$.

[9] Shou, Q.Y. (2003) Study Foreign Experience to Advance China’s District Heating and Cooling. Fluid Machinery, 31, 47-48.

[10] Ju, Y.P., Zhang, Y.Q., Lv, C. and Liu, Y.H. (1996) Energy Saving Effect And Economic Feasible of Air-Source Heat Pumps. Journal of Tianjin University, 29, 750-757.

[11] Liu, D. (2003) Economic Analyses and Application of Water Source Heat Pump System. Tianjin University, Tianjin, $1-90$.

[12] Nagano, K., Kinumura, T., Nakamura, M., et al. (2011) Ground Source Heat Pumps System for Net Zero Energy House. Proceedings of the 10th IEA Heat Pump Conference, Tokyo, 16-19 May 2011, 251-259.

[13] Itoh, T., Nakayama, K. and Onojima, H. (2011) Design/Engineering of Low $\mathrm{CO}_{2}$ Emission Office Building Using Heat Pump and Thermal Storage. Proceedings of the 10th IEA Heat Pump Conference, Tokyo, 16-19 May 2011, 398-305.

[14] Camdali, U., Bulut, M. and Sozbir, N. (2015) Numerical Modeling of a Ground Source Heat Pump: The Bolu Case. Renewable Energy, 83, 352-361. http://dx.doi.org/10.1016/j.renene.2015.04.030

[15] Hu, B. (2015) Numerical Modeling of a Ground Extremum Seeking Control of COP Optimization for Air-Source Transcritical $\mathrm{CO}_{2}$ Heat Pump Water Heater System. Applied Energy, 147, 361-372. http://dx.doi.org/10.1016/j.apenergy.2015.03.010

[16] Carvalho, A.D., Mendrinosb, D. and De Almeidac, A.T. (2015) Ground Source Heat Pump Carbon Emissions and Primary Energy Reduction Potential for Heating in Buildings in Europe-Results of a Case Study in Portugal. Renewable and Sustainable Energy Reviews, 45, 755-768. http://dx.doi.org/10.1016/j.rser.2015.02.034

[17] Arsalis, A., Kær, S.K. and Nielsen, M.P. (2015) Modeling and Optimization of a Heat-Pump-Assisted High Tempera- 
ture Proton Exchange Membrane Fuel Cell Micro-Combined-Heat-and-Power System for Residential Applications. Applied Energy, 147, 569-581. http://dx.doi.org/10.1016/j.apenergy.2015.03.031

[18] Sichilalu, S.M. and Xia, X.H. (2015) Optimal Energy Control of Grid Tied PV-Diesel-Battery Hybrid System Powering Heat Pump Water Heaters. Solar Energy, 115, 243-254. http://dx.doi.org/10.1016/j.solener.2015.02.028

[19] Alabdulkarem, A., Hwang, Y. and Radermacher, R. (2015) Multi-Functional Heat Pumps Integration in Power Plants for $\mathrm{CO}_{2}$ Capture and Sequestration. Applied Energy, 147, 258-268. http://dx.doi.org/10.1016/j.apenergy.2015.03.003

[20] Girard, A., Gago, E.J., Muneer, T. and Caceres, G. (2015) Higher Ground Source Heat Pump COP in a Residential Building through the Use of Solar Thermal Collectors. Renewable Energy, 80, 26-39. http://dx.doi.org/10.1016/j.renene.2015.01.063

[21] Kondou, C. and Koyamaa, S. (2015) Thermodynamic Assessment of High-Temperature Heat Pumps Using Low-GWP HFO Refrigerants for Heat Recovery. International Journal of Refrigeration, 53, 126-141. http://dx.doi.org/10.1016/j.ijrefrig.2014.09.018

[22] Poulet, P. and Outbib, R. (2015) Energy Production for Dwellings by Using Hybrid Systems Based on Heat Pump Variable Input Power. Applied Energy, 147, 413-429. http://dx.doi.org/10.1016/j.apenergy.2015.03.005

[23] Kummer, H., Füldner, G. and Henninger, S.K. (2015) Versatile Siloxane Based Adsorbent Coatings for Fast Water Adsorption Processes in Thermally Driven Chillers and Heat Pumps. Applied Thermal Engineering, 85, 1-8. http://dx.doi.org/10.1016/j.applthermaleng.2015.03.042 